\title{
The agile village: building well-being and wealth in an era of demand change
}

\author{
Faraz Pouyandeh ${ }^{*}$ and Mojtaba Hosseinalipour
}

Department of Architecture, Shahid Beheshti University, Tehran, Iran

\begin{tabular}{|c|c|}
\hline CHRONICLE & A B S T RACT \\
\hline $\begin{array}{l}\text { Article history: } \\
\text { Received December 28, } 2013 \\
\text { Accepted 4 May 2014 } \\
\text { Available online } \\
\text { May 9 2014 } \\
\text { Keywords: } \\
\text { Agile } \\
\text { Architecture } \\
\text { Village }\end{array}$ & $\begin{array}{l}\text { During the past few years, there have been tremendous changes on customer preferences on the } \\
\text { architectures and design perspectives. There are many cases where there are big differences } \\
\text { between what originally a plan is designed for and what it comes in final stage. Obviously, this } \\
\text { may create significant amount of rework, waste and it can increase the cost of building a house, } \\
\text { significantly. This paper presents an empirical investigation on factors influencing change in } \\
\text { architecture of buildings. The proposed study designs a questionnaire in Likert scale and } \\
\text { distributes it among some experts at difference universities in Iran. The study categorizes } \\
\text { different factors in terms of "factors reducing change in clients' request", "methods on } \\
\text { predicting clients' request", "methods on presenting plans for clients", "Effective parameters on } \\
\text { change in plan" and finally "Important actions on change prevention". Using experts' insight, } \\
\text { the study ranks various factors in each category. }\end{array}$ \\
\hline
\end{tabular}

\section{Introduction}

Design management plays essential role in the construction industry and construction firms because of the failure of other existing systems to reach proper integration of the design and construction processes are accomplishing it (Markus \& Arch, 1973; Lawson, 2006; Koch, 2005). Andersen et al. (2005) performed a survey on a design management in an international construction company and compared the results with conceptions devised from literature in order to explain the design management practices. This was accomplished in order to provide a foundation, which can be applied to build coordinated design and construction in complex one-off engineering projects. They compared three conceptions of design management including design management as 'integrators of design and construction'; design management as 'managers'; and design management as 'meta designers' and compared them with several case studies conducted on different projects (Lavers, 1992). Early results indicated that during the operational stages of a project, design management perspectives could be conceived as 'meta designers' rather than as 'managers'.

\footnotetext{
*Corresponding author. Tel:+98912-3122750

E-mail addresses: faraz.pouyandeh@gmail.com (F. Pouyandeh) 
During the past few years, there have been various attempts on the essence of constructing design process and management for building sustainability in the creation and maintenance of a qualitative architectural product. Fadamiro, J. A., \& Bobadoye, S. (2006), for instance, performed a survey on the design process, concept of making sustainability and specifically the quality of the built environment for a state capital in Nigeria as a case study. They examined the basic rules and indicators for sustainability of buildings and its implications on the quality of the environment. Their findings include the views of the professionals on the clients, perception on the design perspectives as well as management of various projects, and the implications on the quality of the ensuring products and the environment (Holgate, 1992). They reported that five factors were effective, with one of them exhibiting the biggest variability and individual differences. Their findings also disclosed the professionals' wrong behavior towards design process as demonstrated with a very high degree of variability in the study. They provided some recommendations on the enactment and enforcement of relevant policies with sufficient education of the people and the involvement of all the stakeholders in the management of building projects and environmental programs for the realization of a qualitative architectural product.

ØyEN (2007) identified possible areas within the course of the design process where building defects were likely to originate, and where preventive measures most likely could be effective. They applied the work on part of project 12 Weather Protection in the Construction Process. They described the architects' basis of knowledge, application of competence and method to technical challenges and necessities implemented to design and to design management. They presented a discourse based on a theoretical foundation of selected issues. Their objective was also to detect possible areas or occasions within the course of the design process where such defects were likely to originate, and where preventive measures most likely could be effective.

According to Koskela et al. (2002), the design process may be conceptualized in three ways including transformation of inputs into outputs, as a flow of data through time and space, and finally as a process for building value for customers. There are many case studies and research findings, which indicate that design management in construction is deficient from these perspectives. Koskela et al. (2002) recommended that the implementation of relatively simple, albeit theory-driven, tools could reach major improvements in the process of construction design.

\section{The proposed study}

This paper presents an empirical investigation on factors influencing change in architecture of buildings. The proposed study designs a questionnaire in Likert scale and distributes it among some experts at difference universities in Iran. The population of this survey includes all university professors in the field of Architecture in city of Tehran, Iran. The sample size is calculated as follows,

$n=\frac{N \times z_{\alpha / 2}^{2} \times p \times q}{\varepsilon^{2} \times(N-1)+z_{\alpha / 2}^{2} \times p \times q}$,

where $N$ is the population size, $p=1-q$ represents the yes/no categories, $z_{\alpha / 2}$ is CDF of normal distribution and finally $\varepsilon$ is the error term. Since we have $p=0.5, z_{\alpha / 2}=1.96$ and $N=60$, the number of sample size is calculated as $n=30$. The study categorizes different factors in terms of "factors reducing change in clients' request”, "methods on predicting clients' request”, "methods on providing plans for clients", "Effective parameters on change in plan" and finally "Important actions on change prevention". Using experts' insight, the study ranks various factors in each category. Before, we do the survey, we first present the questionnaire for some experts and ask them to validate the overal questionnaire and then after making some minor changes, we finalized the questionnaire and distribute it among the sample of the survey. 


\section{The results}

In this section, we present the results of our findings on different factors influencing change on Architectures.

\subsection{Factors reducing change in program}

The first item is associated with factors reducing change program. This item consists of 12 factors and Table 1 demonstrates the results of our survey.

\section{Table 1}

The summary of ranking various factors influencing on reducing change in program

\begin{tabular}{lll}
\hline Item & Description & Score \\
\hline 1 & Availability of check list for design & 4.40 \\
2 & Past experience on similar works & 4.29 \\
3 & Having good communication skills & 4.14 \\
4 & Predicting good capabilities of product & 4.13 \\
5 & Client's familiarity with design perspectives and time allocated & 4.00 \\
6 & Client's awareness about details of program prior to execution & 3.86 \\
7 & Having a good insight on client's life style & 3.83 \\
8 & Having appropriate budget plan & 3.27 \\
9 & Prioritizing client's request based on the available budget & 2.93 \\
10 & Sharing client's close relative in design perspective & 2.92 \\
11 & Client's care about the architectural design and plan & 2.92 \\
\hline 12 & Continuous consultation with client & 2.17 \\
\hline
\end{tabular}

As we can observe from the results of Table 1, availability of check list for design is number priority followed by looking at past experience on similar works, having good communication skills and predicting good capabilities of final plan.

\subsection{Methods on predicting clients' request}

The second item is associated with methods on predicting clients' request. This item consists of six factors and Table 2 demonstrates the results of our survey.

\section{Table 2}

The summary of ranking various factors influencing on methods on predicting clients' request

\begin{tabular}{lll}
\hline Item & Description & Score \\
\hline 1 & Talking about client's life style & 4.53 \\
2 & Presenting useful plans and pictures to client & 4.00 \\
3 & Applying Sketch & 3.87 \\
4 & Asking client to show a good existing villa & 3.29 \\
5 & Asking client to show a bad existing villa & 3.09 \\
6 & Asking client to act as partnership & 2.93 \\
\hline
\end{tabular}

As we can observe from the results of Table 2, talking about client life style is number priority followed by presenting useful plans and pictures to client, providing necessary sketches, requesting client to show a good existing villa, requesting client to show a good existing villa and requesting client to act as partnership.

\subsection{Methods on presenting plans for clients}

The third item is associated with methods on presenting plans for clients. This item consists of six factors and Table 3 demonstrates the results of our survey. 
Table 3

The summary of ranking various factors influencing on methods on predicting clients' request

\begin{tabular}{lll}
\hline Item & Description & Score \\
\hline 1 & 3-dimentional pictures & 4.33 \\
2 & Presenting useful model & 4.21 \\
3 & 2-dimentional pictures & 3.87 \\
4 & Sketch & 3.87 \\
5 & Plan and sample & 3.54 \\
6 & Previous sample if exists & 3.53 \\
\hline
\end{tabular}

As we can observe from the results of Table 3, 3-dimentional pictures are the most important factors influencing client's request for any possible change followed by having a physical model, 2dimentional pictures, sketch, plan and sample and the access to previous plans.

\subsection{Factors influencing on change in architectural plan}

The fourth item is associated with factors influencing on change in architectural plan. This item consists of nine factors and Table 4 shows the results of our survey.

\section{Table 4}

The summary of ranking various factors influencing change in architectural plan

\begin{tabular}{lll}
\hline Item & Description & Score \\
\hline 1 & Change in planning & 4.23 \\
2 & Missing some client's request & 4.07 \\
3 & A high cost of building plan & 4.00 \\
4 & Difference between client's request with priorities in plan & 4.00 \\
\hline 5 & Difference between client's interest with architecture & 3.71 \\
6 & Lack of good insight about client's request & 3.67 \\
\hline 7 & Disregarding client's requests & 3.53 \\
\hline 9 & Difference between client's style with architecture & 3.40 \\
\hline
\end{tabular}

According to the results of Table 4, change in planning is number one priority influencing change in architectural plan followed by missing some clients' request, expenses, and differences between client's request with priorities in plan as well as architecture.

\subsection{Method for preventing change in program}

Finally, we have asked our experts to give their insight about methods on reducing change in program and Table 5 shows details of the factors along with scores given to each item. The results of Table 5 specify that Architecture's experiences on prior similar works play essential role on reducing unnecessary reworks followed by getting approval for each stage of program, having good information about social and cultural issues and a good agreement between client and architecture on different issues.

In addition, a good agreement between client and architecture on different issues along with being informed about other important factors, which could be associated with design of plan are among other important factors, which could prevent change in program. In addition, having good information about rules, regulations and standards as well as having past good experiences are considered as other important factors, which are also recommended by other researchers (Nkwogu, 2001). 
Table 5

The summary of ranking various factors on how to prevent change in program

\begin{tabular}{lll}
\hline Item & Description & Score \\
\hline 1 & Architecture's experiences on prior similar works & 4.73 \\
2 & Getting approval for each stage of program & 4.38 \\
3 & Having good information about social and cultural issues & 4.20 \\
4 & A good agreement between client and architecture on different issues & 4.15 \\
5 & Being informed about other important factors, which could be associated with design of plan & 4.15 \\
6 & Capability of separating the main interests from other issues & 4.07 \\
7 & Capability of detecting clients' hidden requests & 4.07 \\
8 & Having good information about rules, regulations and standards & 3.87 \\
9 & Having past good experiences & 3.64 \\
10 & Creativity on design perspectives & 3.64 \\
\hline 11 & Consultation with other colleagues & 3.53 \\
\hline 12 & Cost and details of contract & 3.53 \\
\hline
\end{tabular}

\section{Conclusion}

There is no doubt that any change on design perspective may influence final plan, significantly and it is important to have a comprehensive insight about the factors affecting client's request in construction projects. In this paper, we have presented a survey on detecting what may influence the most on architectural perspectives of building a villa in Iran and how to reduce any unnecessary changes on plans. The study categorizes different factors in terms of "factors reducing change in clients' request”, "methods on predicting clients' request”, "methods on presenting plans for clients", "Effective parameters on change in plan" and finally "Important actions on change prevention". Using experts' insight, the study ranks various factors in each category. In our survey, Architecture's experiences on prior similar works play essential role on reducing unnecessary reworks followed by getting approval for each stage of program, having good information about social and cultural issues and a good agreement between client and architecture on different issues.

\section{Acknowledgement}

The authors would like to thank the anonymous referees for constructive comments on earlier version of this paper. We are also delighted for insights gathered from university professors at Shahid Beheshti university.

\section{References}

Andersen, J., Nycyk, M., Jolly, L., \& Radcliffe, D. (2005). Design management in a construction company. In ICED 05: 15th International Conference on Engineering Design: Engineering Design and the Global Economy (p. 2494). Engineers Australia.

Fadamiro, J. A., \& Bobadoye, S. (2006). Managing the building design process for sustainability and improved quality. Civil Engineering Dimension, 8(1), 1-7.

Holgate, A. (1992). Aesthetics of built form (p. 7248). New York: Oxford University Press.

Koch, A. S. (2005). Agile software development: evaluating the methods for your organization. Boston: Artech house.

Koskela, L., Huovila, P., \& Leinonen, J. (2002). Design management in building construction: from theory to practice. Journal of Construction Research, 3(01), 1-16.

Lavers, A. (1992). Communication and clarification between designer and client: good practice and legal obligation. Architectural Management, 22-28.

Lawson, B. (2006). How designers think: the design process demystified. Routledge.

Markus, T., \& Arch, M. (1973). Optimisation by evaluation in the appraisal of buildings. Value in Building: Applied Science, 88-111. 
1190

Nkwogu, U. O. (2001). Understanding Theory and Appreciating Criticism in Architecture. Architects and Architecture in Nigeria, Association of Architectural Educators in Nigeria, 123-144.

ØyEN, C. F. (2007). Design process challenges-Simple obstacles or complex building defects?. Project report, 1. 